\title{
EL ARTE JUARENSE FRENTE A LAS DESAPARICIONES FORZADAS
}

\section{ART OF JUAREZ AGAINST ENFORCED DISAPPEARANCES}

\author{
HoRTENSIA MínGuez Garcia / horteminguez@gmail.com \\ Instituto de Arquitectura, Diseño y Arte. Universidad Autónoma de Ciudad Juárez. México \\ Judith ZamarRIPA NungaRAY / judithzn0401@gmail.com \\ Ciudad Juárez. México
}

Recibido 6/1/2020 | Aceptado 11/4/2020

\section{RESUMEN}

El presente texto tiene como objeto describir cómo en el arte se desarrollan temáticas relativas a la violencia, tomando como estudio de caso los libros de la artista juarense Olga Guerra, que se centran en las desapariciones forzadas acontecidas en esta ciudad. Para ello, se refiere primero el estado de la cuestión de este extendido problema en la geografía mexicana en general y del territorio juarense en particular, para luego exponer las estrategias con las que los artistas abordan esta problemática desde la teoría de la estética relacional, en aras de construir espacios que favorezcan las interrelaciones humanas para la reconstrucción del tejido social.

\section{PALABRAS CLAVE}

Olga Guerra; desapariciones forzadas; arte; Ciudad Juárez; estética relacional

\section{ABSTRACT}

The purpose of this text is to describe how art develops themes related to violence, taking as a case study the books of the artist from Olga Guerra, who focuses on the forced disappearances that took place in this city. For this, the state of the question of this widespread problem in Mexican geography in general, and of the territory of Juarez in particular, is referred to first; to then expose the strategies with which artists approach this problem from the theory of relational aesthetics, in order to build spaces that favor human interrelations for the reconstruction of the social fabric.

\section{KEYWORDS}

Olga Guerra; forced disappearances; art; Ciudad Juarez; relational aesthetics 
«Pienso, luego me desaparecen.» Massive Attack (2014)

Esta frase popular "pienso, luego me desaparecen», ${ }^{1}$ viene a condensar el candente e insondable arraigo histórico que el fenómeno de las desapariciones forzadas tiene en México. Las desapariciones forzadas constituyen un atentado directo contra múltiples artículos de la Declaración Universal de los Derechos Humanos en términos de usurpación de la libertad, imposición y degradación; lo cual nos lleva básicamente a hablar de violencia. Según la Declaración sobre la protección de todas las personas contras las desapariciones forzadas, emitida por la Organización de las Naciones Unidas (ONU), se considera desaparición forzada o involuntaria cuando:

[...] se arreste, detenga o traslade contra su voluntad a las personas, o que éstas resulten privadas de su libertad de alguna otra forma por agentes gubernamentales de cualquier sector o nivel, por grupos organizados o por particulares que actúan en nombre del Gobierno o con su apoyo directo o indirecto, su autorización o su asentimiento, y que luego se niegan a revelar la suerte o el paradero de esas personas o a reconocer que están privadas de la libertad, sustrayéndolas así a la protección de la ley (Resolución 47/133, 1992, p. 1).

Las Desapariciones Forzadas son un crimen contra la humanidad, un problema que no prescribe y que puede llegar a impactar de manera directa o indirecta a toda la población civil. No importa la condición de género, el nivel socioeconómico o la inclinación ideológica o religiosa: nadie queda excluido de esta problemática, pues las desapariciones forzadas encaminan a la sociedad a un estado psicosocial de inseguridad, de perturbación y de desamparo constante que no solo afecta al desaparecido, sino también a los familiares y a los amigos en lo emocional, y los margina legalmente. ${ }^{2}$

La problemática de las desapariciones forzadas posee un alto índice de casos por resolver en México. Cuando este país se avino al examen periódico del Comité contra las Desapariciones Forzadas (CED) de la ONU el 2 y 3 de febrero del 2015 en Ginebra, Suiza, no solo acarreaba la sorprendente cifra de más de cien mil muertes

1 La frase fue popularizada por el grupo Massive Attack, banda musical británica que proyectó imágenes y frases de este estilo en su concierto en octubre de 2014, celebrado en la Plaza de la Condesa en la Ciudad de México, para denunciar lo acontecido.

2 «La familia y los amigos de las personas desaparecidas sufren una angustia mental lenta, ignorando si la víctima vive aún y, de ser así, dónde se encuentra recluida, en qué condiciones y cuál es su estado de salud. [...] Además, no saben cuándo va a regresar, si es que regresa, el ser querido, lo que dificulta su adaptación a la nueva situación. En algunos casos, la legislación nacional puede hacer imposible recibir pensiones u otras ayudas si no existe un certificado de defunción. El resultado es a menudo la marginación económica y social» (Naciones Unidas, 2009, p. 2). 


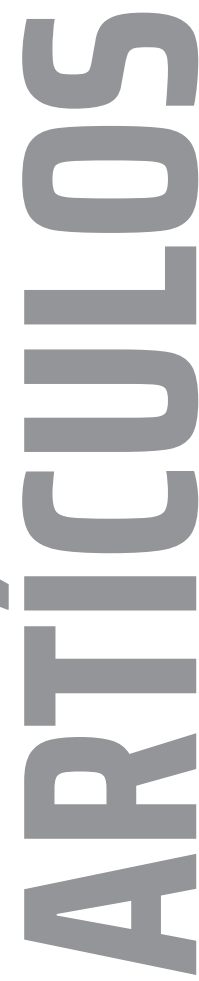

"como consecuencia de la guerra entre cárteles y de la situación de violencia generalizada y represión en México, sino que no poseía estadísticas concretas acerca del tema» (Molina, 2015, s. p.).

Razón suficiente para que el CED tildara a México de vivir en una situación vivencial generalizada de desapariciones y para que exigiera una solución estructural a la falta de un registro confiable que permitiera determinar si se trataba de desapariciones o de desapariciones forzadas, así como medidas legales pertinentes y punitivas que aseguraran la imparcialidad de las investigaciones y que atendieran debida e integralmente el problema jurídico y psicosocial de las desapariciones forzadas. En la actualidad, esta postura de desatención política y legislativa mexicana ha comenzado a cambiar. ${ }^{3}$ El 10 de julio de 2015 se publicó en el Diario Oficial de la Federación un avance: la reforma al artículo 73 de la Constitución, que faculta al Congreso de la Unión a legislar sobre la materia; lo cual nos lleva a hablar de nuestro actual estado de transitoriedad respecto a la futura aprobación de una Ley General sobre Desapariciones Forzadas.

Esto supone un avance, aunque los tiempos no parecen ser oportunos. Así lo atestigua el Grupo de Trabajo sobre Desapariciones Forzadas o Involuntarias de Naciones Unidas, que en septiembre de 2015 presentó su informe de seguimiento a las recomendaciones que la ONU emitió en Ginebra en torno al tema. En este documento, los miembros lamentaron «la situación deteriorada que prevalece en México» y «los pocos avances en la implementación de las recomendaciones realizadas» (Grupo de Trabajo sobre Desapariciones Forzadas o Involuntarias, 2015, p. 3). Así, aunque el Grupo valoraba que «la emisión de varias leyes a nivel local en materia de desapariciones forzadas, dio la bienvenida a la reforma constitucional del 2015», advertía que, en México, «la impunidad generalizada perdura como un patrón crónico» (Grupo de Trabajo sobre Desapariciones Forzadas o Involuntarias, 2015 , p. 5). No hay más que recordar lo acontecido con la tragedia del caso de los 43 estudiantes de Ayotzinapa. ${ }^{4}$

Para abril de 2016, luego de que el Senado presentara un borrador de la nueva Ley General sobre Desapariciones Forzadas en México, diferentes asociaciones y organizaciones no gubernamentales (ONG) seguían mostrando su inconformidad acerca de cómo se abordaba el tema en México:

3 Este cambio se debe a las múltiples protestas y comunicados por parte de la sociedad organizada: Amnistía Internacional, Comisión Mexicana de defensa y Promoción de los derechos Humanos (CMDPDH), el Centro de Derechos Humanos Miguel Agustín Pro Juárez (PRODH), entre otras.

4 El caso Ayotzinapa ocurrió en Iguala (Guerrero, México), en el año 2014. Los días 26 y 27 de septiembre se enfrentó la policía municipal con civiles. Resultado: nueve personas fallecidas, decenas de heridos y la desaparición de más de cuarenta estudiantes de la Escuela Normal Rural de Ayotzinapa. Finalmente, declaraciones de integrantes de la organización criminal Guerreros Unidos y el hallazgo de restos humanos y evidencias varias en el vertedero municipal y río de Cocula, apuntan a que los alumnos fueron asesinados, incinerados y, luego, lanzadas sus cenizas al río San Juan. Continúa sin esclarecerse el caso. 


\begin{abstract}
[...] agrupadas bajo la Campaña Nacional Contra la Desaparición Forzada, emitieron un posicionamiento en el que aseguran que el borrador "parte del supuesto de que la mayoría de las personas que han sido desaparecidas en México» lo han sido a manos de particulares y no por agentes del Estado. De esta forma, el texto, elaborado por diferentes comisiones del Senado, no se ajusta a los estándares internacionales en materia de derechos humanos; elude la responsabilidad de las autoridades [...]. La expresión «desaparición forzada», explican, se refiere a aquellas cometidas «de manera directa o indirecta por agentes del Estado o por grupos que actúan con su consentimiento o aquiescencia». Por tanto, el Estado es el «único responsable de proteger, garantizar y respetar los derechos humanos e investigar, sancionar y reparar toda desaparición forzada» (EFE, 2016, s. p.).
\end{abstract}

No obstante, las desapariciones forzadas en México no pueden considerarse parte de un fenómeno anómico puesto que sí existen normas, leyes, estructuras gubernamentales y otros organismos a nivel internacional que pueden fiscalizar, paliar o, al menos, registrar los diferentes tipos de prácticas ilegales o conductas inhumanas o desviadas: el problema se estima que radica en la vinculación del gobierno con el crimen organizado y, por tanto, la inacción oficial; resultados que emiten diferentes evaluaciones de la ONU y otros organismos para México.

En concordancia con lo anterior, a las autoridades locales y de todos los niveles se les vincula directa o indirectamente con desapariciones forzadas, feminicidios y otra serie de homicidios en contextos como el de Ciudad Juárez, donde priva la ineficacia del gobierno y su notoria corrupción.

\title{
EL CONTEXTO DE LAS DESAPARICIONES EN CIUDAD JUÁREZ
}

Antes de aventurarnos a hablar del arte como resistencia al olvido y de la obra de Olga Guerra, en particular, como una de las posibles formas de actuar artísticamente frente a contextos que permanecen en una especie de statu quo o estado de violencia sistematizada, ${ }^{5}$ dedicaremos un pequeño espacio para revisar el caso de Ciudad Juárez y cómo se encuentra actualmente esta urbe respecto al tema de las desapariciones forzadas y otros delitos derivados del abuso de poder, que incluye retenciones indebidas, torturas, ejecuciones extrajudiciales, casos de feminicidios, etcétera.

Con una extensión de $188 \mathrm{~km}^{2}$ y más de un millón y medio de habitantes, Ciudad Juárez se ubica al norte de México, prácticamente unida a la ciudad de El Paso (Texas). Su ubicación, alejada del centralismo mexicano, ha derivado en una

5 Hacemos alusión a la existencia de un estado de violencia sistematizada porque no se trata de un ejercicio de poder puntual, sino de un contexto generalizado que permea a la sociedad en todas las escalas sociales y económicas durante un periodo de tiempo prolongado. 


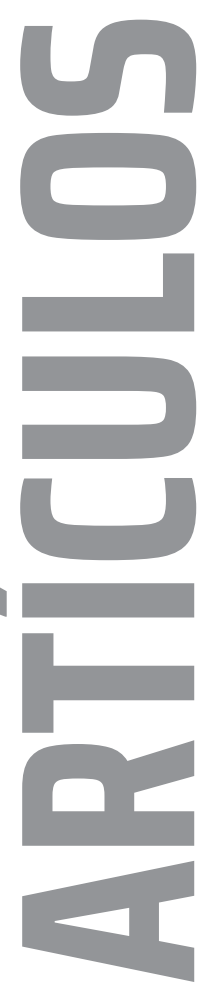

particular forma de comprender la mexicanidad en su cotidiano quehacer fronterizo. No es nuevo oír de los juarenses que Ciudad Juárez siempre ha sido una ciudad laboratorio.

Una ciudad que, consciente o inconscientemente, siempre ha sido el laboratorio de quienes han inducido a este pueblo mexicano a arriesgar estructuralmente su modelo económico ante su falta de recursos e infraestructura, a cambio de un dinamismo socioeconómico, si no seguro, fluctuante. Así, por ejemplo, podemos remontarnos a diversos sucesos históricos de interdependencia entre México y Estados Unidos: desde la implementación de la Ley Seca en Estados Unidos (19191933), ${ }^{6}$ que convirtió a Ciudad Juárez en el espacio de ocio, vicio y diversión de la sociedad fronteriza, hasta la implementación de programas que indujeron a la ciudad a transformarse en un espacio de suministro de mano de obra barata. Primero, con el Programa Bracero (1942-1965), ${ }^{7}$ y luego con el Programa de Industrialización Fronteriza (PIF) en 1964, ${ }^{8}$ a colación del cual Juárez se aleccionó a un modelo económico fundamentado en la industria maquiladora; situación que generó un alto nivel de contratación y crecimiento acelerado desde mediados de los sesenta hasta el año 2000, pero con una notoria sobreexplotación de trabajadores por lo precario de los empleos.

La dependencia de su modelo económico con respecto a las fluctuaciones del dólar ha sido también determinante para el brote de diferentes crisis económicas por las que Juárez ha transitado — sobre todo en el 2001 y en el 2008_, "que han influido en la dinámica socioeconómica de la ciudad, así como en la imagen negativa que se ha construido sobre ésta» (Barrios Rodríguez, 2013, p. 85).

Ciudad Juárez es y ha sido desde tiempos remotos una ciudad estigmatizada por estos y por otros muchos problemas. Por ejemplo, su posición geográfica y geopolítica, si bien ha sido una ventaja para el tránsito comercial y migratorio y, por ende, para el crecimiento demográfico y socioeconómico de la ciudad, también ha sido su talón de Aquiles; escenario complejo y altamente contrastante. Juárez es un espacio paceño entre el tercer y el primer mundo, rico por sus intercambios migratorios y contrastes brillantes en sentido étnico y cultural pero que, como espacio fronterizo, también concierta ser un lugar estratégicamente codiciado; especialmente para quienes ostentan controlar el poder de ese

6 «La ley Volstead (o ley seca), prohibió la venta, importación y fabricación de alcohol en todo el país norteamericano» (García Pereira, 2010, p. 26).

7 El programa Bracero fue el Primer Acuerdo Internacional de Trabajadores firmado en 1942 entre México y Estados Unidos, que proveía de mano de obra mexicana a las zonas agrícolas del sur de Estados Unidos; derogado en 1965 por el país del norte.

8 México permitió la instalación de plantas industriales norteamericanas en la franja fronteriza, que brindaran empleo a mexicanos, pues había altos niveles de desempleo en población asentada en aquella franja debido al cierre del programa Bracero. A finales de 1992, Canadá, México y Estados Unidos firmaron el Tratado de Libre Comercio de América del Norte (NAFTA) que nuevamente impulsó la industria maquiladora en el norte de México. 


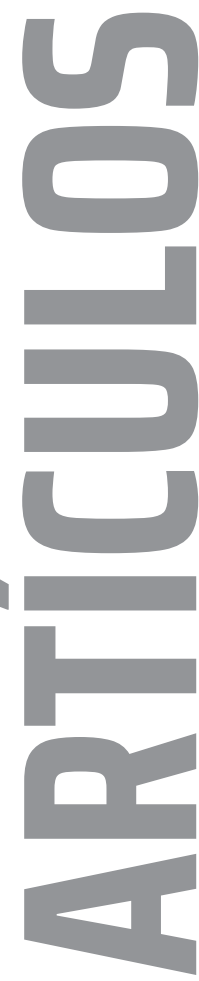

puente tan privilegiado para todo tipo de negocios. Comercio legal o no, poseer el control territorial de la frontera juarense ha sido un enclave importantísimo para comprender la permanente disputa entre los cárteles como el de Sinaloa y el de Juárez, entre el manejo de situaciones que sobrepasan la ley y permean la impunidad. Poseer el control fronterizo entre las dos Américas supone dominar el tráfico de drogas entre Latinoamérica y Norteamérica.

Bajo un contexto que aglutina problemas inherentes al modelo económico dependiente y fluctuante que deriva en empleo precario, además de poca inversión en infraestructura y educación para una sociedad tan variable numérica y culturalmente, la frágil situación de Ciudad Juárez se complejizó en el año 2006, con el gobierno de Felipe Calderón, al iniciar la conocida guerra contra el narcotráfico; situación bélica que sitió y sometió a esta ciudad a un estado de violencia sistematizada. Los homicidios en Ciudad Juárez se incrementaron alarmantemente; tendencia que continuó al alza en los dos años siguientes, sumando más de diez mil muertos de 2006 a 2008 en esa ciudad; un nivel de atrocidad solo comparable con el de una guerra civil. ${ }^{9}$

Ciudad Juárez es testigo, además, de feminicidios, ${ }^{10}$ desapariciones forzadas, limpieza social, ${ }^{11}$ delincuencia organizada, intimidaciones, secuestros y extorsiones múltiples, sobre todo por pago de cuotas a todo tipo de empresarios. Un contexto que, además de generalizar un estado tendiente a una socialidad de resguardo (Salazar \& Curiel, 2012) y a la reclusión familiar, modificó nuestras prácticas cotidianas como el salir a pasear al parque con los niños; y más aún la confiabilidad de autoridades como la policía, el ejército, etcétera.

Cuando Felipe Calderón envió al Operativo Conjunto Chihuahua (OCCH) a Ciudad Juárez, ${ }^{12}$ su estrategia militar fue custodiar la ciudad, a la par que desarticular los cárteles implicados en el narcotráfico. Sin embargo, después de varios años «el aumento de denuncias por violaciones a los derechos humanos fue considerable»

9 «Las 80 mil muertes y los 22 mil desaparecidos atribuibles a la guerra contra el narco entre 2008 y 2013 en México entran en el rango numérico de conflictos bélicos recientes. Son una cifra muy superior a las 23 mil bajas en combate de la primera Guerra del Golfo de 1990-91, y a las 50 mil de la guerra entre Etiopía y Eritrea de 1998-2000. Están en la escala de los 112 mil civiles muertos en Irak, durante la segunda Guerra del Golfo de 2002. Son cifras de violencia sin precedente en el México moderno» (Molina, 2015, s. p.)

10 Aunque es incierto cuándo se iniciaron los feminicidios en Ciudad Juárez, se suelen fechar en 1993, por ser el año en el que aparecieron los primeros cuerpos de mujeres jóvenes asesinadas, torturadas y mutiladas con el mismo modus operandi. Se les atribuyen al crimen organizado, al parecer para rituales de operatividad o de iniciación. Se estima la cifra en 400 asesinadas y 1000 desaparecidas.

11 Limpieza social refiere a la eliminación de determinados miembros de la sociedad bajo un supuesto criterio por suponer una molestia, carga u oposición incómoda, por escasez de recursos. Los mayormente afectados han sido enfermos terminales, homeless, ancianos y otras minorías. 12 Operativo antidroga formado por miembros del ejército y fuerzas federales, de inicio 2026 y luego llegó a 7000; aunque el gobierno federal dijo que eran 10000 efectivos (Villalpando, 2010, p. 7). 


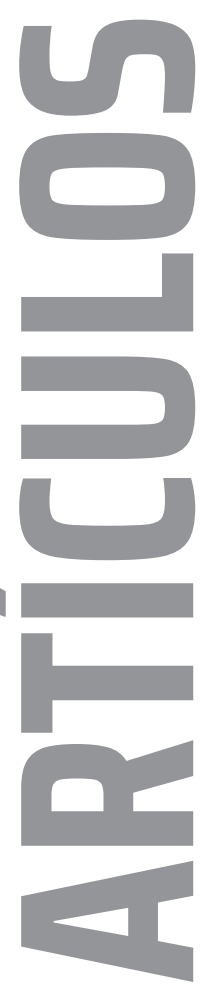

(Martínez Toyes \& Arellano Quiroga, 2013, p. 48). Por ejemplo, «La Comisión Nacional de los Derechos Humanos (CNDH) afirmó que en 2006 recibió 182 quejas contra la Secretaría de la Defensa Nacional (SEDENA); en 2007, 367 quejas; en 2008, 1230; y durante los seis primeros meses de 2009 la cifra ya ascendía a 559» (Amnistía Internacional, 2009, p. 9). Para el año 2010 el gobierno cambió su estrategia: anunció la salida del ejército y la custodia de la ciudad pasó a manos de la Policía Federal.

Los abusos de poder detrás de estas miles de denuncias contra militares y policías no son más que datos variables, pues como ya anotaría en su momento la Comisión Estatal de Derechos Humanos y Amnistía Internacional, son cifras que «no reflejan el verdadero número de casos de tortura, desaparición forzada y homicidio ilegítimo» (Amnistía Internacional, 2009, p. 6). Mucho menos el daño indirecto, pues «Juárez, junto a otras ciudades del país, fue gravemente afectada por esta ola de violencia que ha dejado a su paso más de 9500 muertes, cerca de 10000 huérfanos y miles de víctimas indirectas» (Martínez Toyes \& Arellano Quiroga, 2012, p. 46), además de aumento en el desempleo y emigración de una inmensa cantidad de pobladores juarense, quienes abandonaron sus hogares y patrimonios por motivos de inseguridad, partiendo hacia otras regiones del país o a El Paso, Texas. ${ }^{13}$

En la actualidad, aunque los juarenses ya parecen haber salido de este estado de desasosiego y reclusión social generalizado, como ciudadanos, siguen en duelo pues muchos de ellos experimentaron la pérdida de conocidos o seres cercanos.

\section{EL ARTE DE LA MEMORIA COMO FORMA DE RESISTENCIA}

«Pero hay una manera de contribuir a la protección de la humanidad, y es no resignarse. No mirar con indiferencia cómo desaparecen de nuestra mirada la infinita riqueza que forma el universo que nos rodea, con sus colores, sonidos y perfumes." Ernesto Sábato (2006)

El tema de la memoria ha sido punto de mira para el mundo del arte desde los años sesenta en relación con el concepto de otredad y la recuperación del recuerdo como forma de resistencia. El interés de los artistas por reconstruir la memoria de los otros: los colonizados, las etnias, las minorías, los vencidos, los marginados,

13 «[...] en este periodo de violencia e inseguridad, 230000 personas se fueron de Ciudad Juárez. [...] La zona de mayor expulsión fue el suroriente, lo que coincide con que es la zona que presenta más casas abandonadas en la ciudad (53\% de un total de 32,868 viviendas en abandono)» (Martínez Toyes \& Arellano Quiroga, 2013, p. 58). María del Socorro Velázquez Vargas, responsable de la Encuesta de Viviendas Deshabitadas (ENVIDES-2010) que realizó el Centro de Investigaciones Sociales (CIS) de la Universidad Autónoma de Ciudad Juárez, afirma que cabría sumar otras 43000 viviendas que se registraron como deshabitadas (Velázquez Vargas \& Martínez Canizales, 2012). 


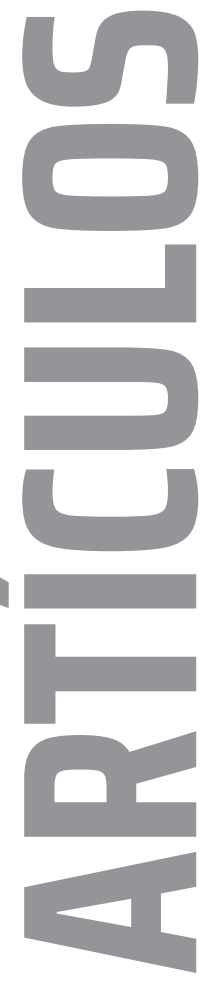

los migrantes, los desaparecidos, etcétera tuvo que ver, originalmente, con el deseo de no perder aquellos vínculos sociales y enseñanzas de vida de quienes vivieron situaciones extremas como catástrofes, guerras u holocaustos; pero, sobre todo, con una práctica de resistencia frente al olvido de la mayoría de la sociedad, de su identidad y de su pasado.

Como ya anotó Anna María Guasch (2005), hablar de la memoria se popularizó a manos de infinitud de artistas desde múltiples perspectivas. Algunos se centraron en la recuperación de la memoria biográfica y privada, como harían Sophie Calle o Nan Goldin (Guasch, 2005), la memoria social ${ }^{14} \mathrm{o}$ a la posmemoria. ${ }^{15}$

Este tipo de obras artísticas buscan mapear y reconstruir la memoria de un suceso o de una persona a través del ensamblaje de elementos como fotografías, grabaciones, documentos, vestimenta u otro tipo de objetos, en aras de facilitar, en el espectador, un enlace simbólico entre estos y el pasado: lo ausente. En resumen, un afán documental virado hacia la reconstrucción de la memoria a través de recuerdos latentes, el poder pregnante y mnemotécnico de los objetos y de las imágenes en general.

En ese tenor, a partir de la memoria como tema y la práctica archivística como método, los artistas requieren acercarse a la problemática en persona. En primer lugar, ponerse en contacto con los sujetos implicados directa o indirectamente y sumergirse en su cotidianidad; no solo mediante la escucha, sino convivir y participar de manera activa en su contexto, en sus sentimientos y en sus luchas. En suma, son artistas que manejan procesos creativos exógenos, ya que se tornan dependientes de la comunidad con la que requieren dialogar y colaborar para la consecución de sus piezas; en principio como denuncia, y a la postre como práctica terapéutica que visiblemente se proyecta bajo el ideal de reconstruir la membrana social por medio de la eclosión de una estética relacional. ${ }^{16}$

14 La memoria social es aquella que cohabita en nuestras prácticas cotidianas, rituales y costumbres y que por lógica conservamos a través del manejo de múltiples actividades que nos permiten recordarlas si las realizamos con cierta asiduidad (Halbwachs, [1991] 2002).

15 Neologismo que alude a la reconstrucción de una memoria fragmentada tras el acontecer de algún suceso inesperado o catastrófico como genocidios, homicidios, retenciones indebidas y arbitrarias, sometimientos, desapariciones forzadas, torturas y ejecuciones extrajudiciales. En esta categoría se ubican artistas como Christian Boltanski, Hans-Peter Feldmann, Art Spiegelman o Shimon Attie; que coinciden en su forma de postularse a través del archivo en el sentido foucaultiano de la enunciabilidad, como el resultado de esa pulsión de combatir el olvido, lo vacuo.

16 Estas prácticas se pueden circunscribir a la teoría de la estética relacional de Nicolas Bourriaud (2008), centrada en comprender la interrelación entre lo humano, las situaciones y los encuentros: «la posibilidad de un arte relacional —un arte que tomaría como horizonte teórico la esfera de las interacciones humanas y su contexto social, más que la afirmación de un espacio simbólico autónomo y privado - da cuenta de un cambio radical de los objetivos estéticos, culturales y políticos puestos en juego por el arte moderno» (p. 13) 


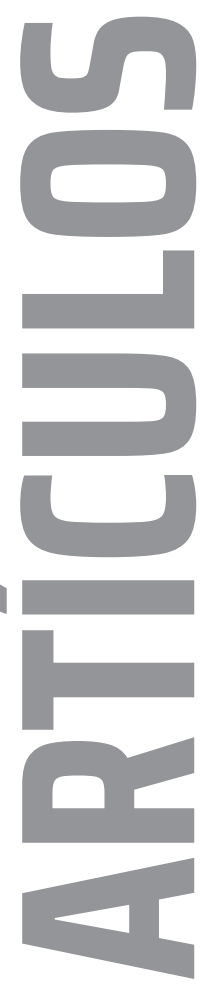

En el contexto violento de Ciudad Juárez, ya reseñado, hay diversas propuestas de artistas como Guerra, Cesario Tarín o el artista urbano Mac, quienes básicamente han tipografiado diferentes formas artísticas de atender la recuperación de la memoria de personas desaparecidas; ya sea a través de la creación de libros de artista, del arte objetual o del uso de estrategias poético conceptuales inherentes al arte: archivo, de Guerra; tácticas performáticas, de Cesario Tarín; y los murales del artista urbano Mac.

Para muchos de estos artistas, esta forma de resistencia está ligada con las «poéticas de lo afectivo - tomando esta afección como una estrategia estética del devenir disidente-» (Méndez Llopis, 2016, p. 118) en las que, más allá de la intención del simple hecho enunciativo, los artistas buscan generar espacios de acontecimiento y de «participación en la afección de lo social» (Herrera \& Olaya, 2011, p. 114).

A continuación, revisaremos la obra de una de las artistas referida, Olga Guerra.

\section{OLGA GUERRA (CIUDAD JUÁREZ, CHIH., MÉXICO, 1990)}

Olga Daniela Guerra Díaz se define como artista, feminista y defensora de los derechos humanos. ${ }^{17}$ La mayoría de sus piezas se centran en la problemática de las desapariciones, los feminicidios y las víctimas de muertes violentas relacionadas con la guerra contra el narcotráfico en general. En sus piezas podemos ver claramente la construcción de microrrelatos e historias de vida desde la visión de los familiares de las víctimas o desde la cotidianidad de los mismos victimados. La intención de Guerra, ante todo, es la de ofrecer un nuevo sentido a sus muertes o a los sucesos que dichas personas vivieron.

Una de sus piezas más populares es Fragmentos de Oposición al Olvido (2012) [Figura 1]. Sin necesidad de mostrar rostros o nombres de las víctimas, Guerra rememora la identidad que les fue arrebatada por medio de objetos que formaban parte de su cotidianidad:

Los objetos que pertenecían a las víctimas de muerte violenta están ahí, dentro de 10 vitrinas de madera y cristal, que hablan de una persona sin mencionar su nombre, sin decir cómo la asesinaron. La exhibición nos habla de la carga simbólica que tiene cada objeto, en apariencia, insignificante (Guerra, comunicación personal, 23 de septiembre de 2015)

17 Además de la licenciatura en Artes Visuales por la Universidad Autónoma de Ciudad Juárez, Guerra cursó en 2013 un diplomado en Acompañamiento psicosocial a víctimas de violación de los derechos humanos en el Centro de Derechos Humanos de las Mujeres (CEDEHM), en Chihuahua, México. 

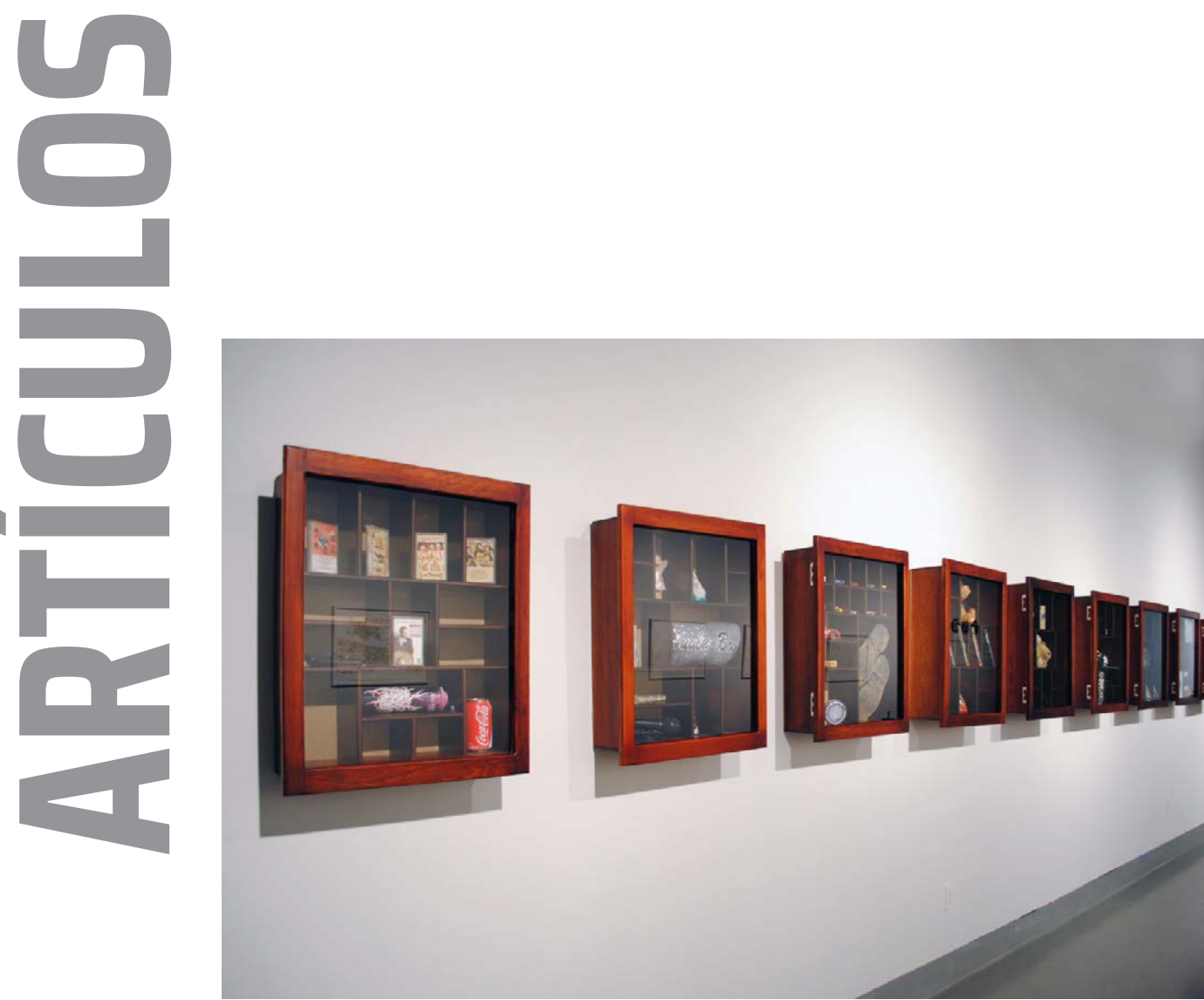

Figura 1. Fragmentos de Oposición al Olvido (2012), de Olga Guerra. Instalación de arte objeto. Vitrinas de $50 \times 65 \mathrm{~cm}$. Imágenes: cortesía de la artista

En esta obra, la artista intenta que el espectador deje de ver a las víctimas como ajenas "como un ente aislado, lejano, irreconocible más que en lo efímero de la nota roja o las cifras que los medios imponen", ya que por medio de los objetos expuestos genera «vínculos de identidad; es decir, aquello que se exhibe en las vitrinas es algo que "yo también uso". La obra permite un acercamiento a la muerte violenta desde lo humano, lo común» (0. Guerra, comunicación personal, 23 de septiembre de 2015). Asimismo, a través de la exposición de estas diez vitrinas, la autora busca construir espacios concretos que permitan la interrelación y el diálogo entre diferentes sujetos de la realidad juarense, desde los familiares directos de los desaparecidos o fallecidos, hasta la comunidad en general.

En otras piezas como Cartas a la ausencia (2014) [Figuras 2a, 2b y 2c], Guerra realiza una especie de archivo de despedidas, a través de las palabras de duelo de los familiares quienes, motivados por la idea de recuperar la memoria de las víctimas, escribieron una serie de cartas que no solo ayudaban a las familias a encontrar paz, sino a convertir la muerte o desaparición violenta en poesía: «Es un archivo escrito y recopilado por los deudos, [...] una producción desde su necesidad de expresar y de sanar, en términos de Carlos Martín Beristain, respecto a la superación del trauma a través de la escritura» (O. Guerra, comunicación personal, 23 de septiembre de 2015). En ese sentido, Cartas a la ausencia (2014) son un conjunto de cartas manuscritas por familiares quienes le escriben directamente a sus desaparecidos o ya fallecidos, hablándoles en primera persona acerca de sus miedos, sus afrentas y pesares, pero también de esperanzas. 


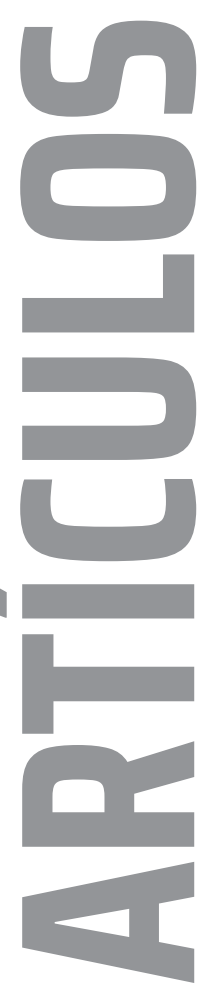

Guerra respeta sus palabras, sus emociones; de ahí la literalidad de los resultados, pues aquello que nosotros vemos son simplemente fotocopias de las cartas. Nuevamente, lo artístico arriba en la construcción del acto, en lo vivencial del hacer y del leer para rememorar, para compartir, para sanar.

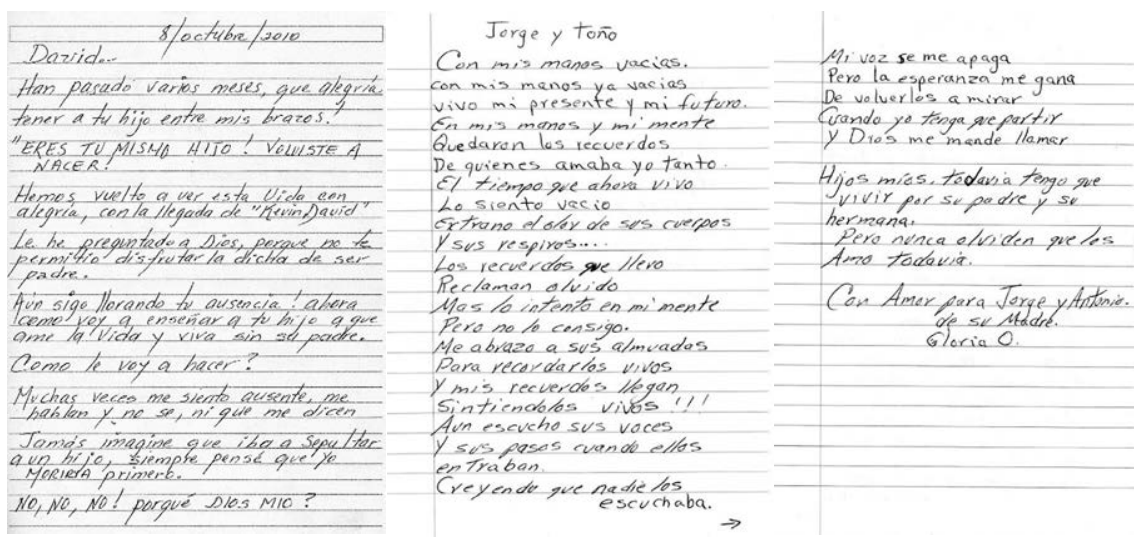

Figuras 2a, 2b y 2c. Cartas a la ausencia (2014), de Olga Guerra. Fotocopias. Dimensiones: $28 \times 21$ cm. Imágenes: cortesía de la autora

Esta forma de reconstrucción de la memoria de las personas desaparecidas o fallecidas a través de recuerdos y de sentimientos manuscritos por sus seres más allegados, también fue un recurso explotado en piezas como Memorias de lo privado a lo político (2013) [Figuras 3 y 4]. Para la construcción de esta pieza, Guerra parte del manejo de fotografías de personas retratadas públicamente en diferentes escenas cotidianas, que posteriormente fueron asesinadas. Se trata de fotografías en las que recortó sus siluetas para sustituirlas por fragmentos de entrevistas hechas a sus familiares, privilegiando así, no la imagen que representa la presencia del difunto, sino la estela que estos realmente dejaron en otros: en lo privado.

Guerra se vale también del libro de artista, también conocido como libro-arte, como medio creativo del que aprovecha las bondades del género artístico inherente al relato, el archivo y la narración de un suceso. Por tratarse de un formato intimista, permite a los lectores revisitar sincrónicamente sus páginas tantas veces como lo deseen y así hacer presente lo que ya quedó en el olvido; propiciando ejercicios terapéuticos que reconcilian a la par que eclipsan, al tiempo que todo lo ausenta.

El género del libro-arte, en su afinidad con el tema de memoria tanto desde la perspectiva más intimista como social, se torna una forma de resistencia, en donde el libro constituye una herencia, un legado mnemotécnico, un lugar para enunciar, para recuperar e inclusive, para liberar a nuestra psique de problemas subyacentes. 


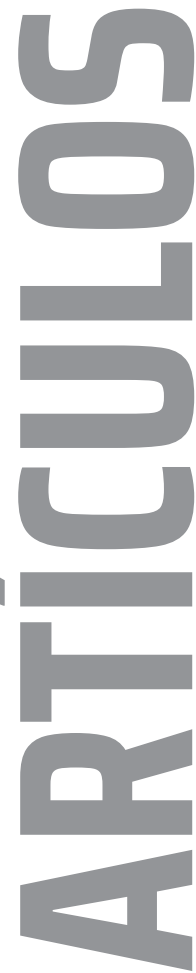

Pero también, un lugar para exhortar el acto de la lectura; al cabo, un acto de conmemoración en sí mismo, una estrategia, un anclaje que, desde el pasado, nos invita a contextualizar e interpretar la obra en sentido anacrónico (Mínguez-García, 2018, p. 537).
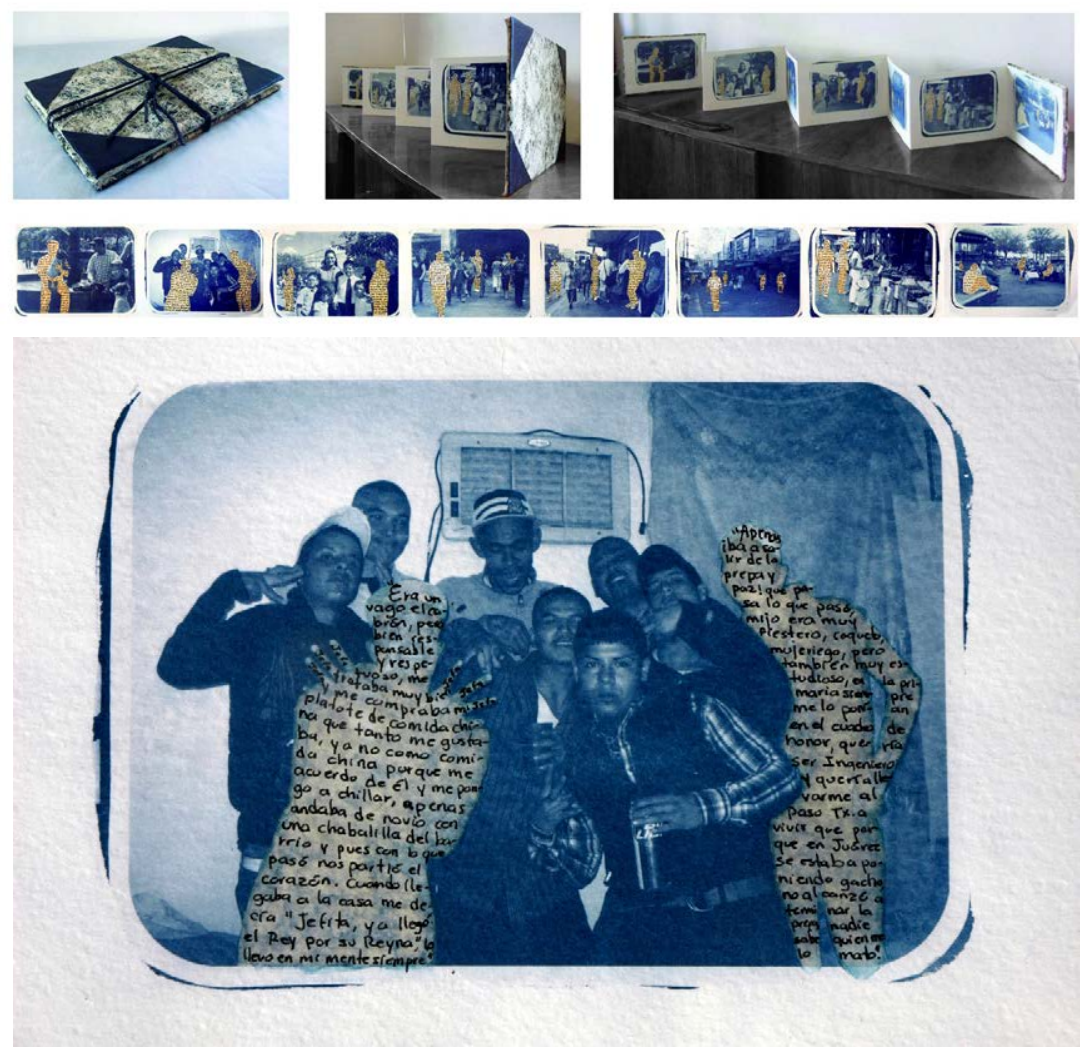

Figuras 3 y 4. Memorias de lo privado a lo político (2013), de Olga Guerra. Libro de artista. Cianotipias y collage. Imágenes: cortesía de la autora

Por último, referimos al libro de artista Sin Título (2012) [Figura 5], de Guerra, para el que recopiló «documentación fotográfica de las pesquisas, pegadas en el centro histórico de Ciudad Juárez en las calles 16 de Septiembre, Avenida Juárez y Mariscal» (O. Guerra, comunicación personal, 23 de septiembre de 2015): carteles de personas desaparecidas que la artista registró durante un año (2012-2013) y que posteriormente recopiló en un libro de cianotipias. Una obra que, según la autora, no está conclusa, de ahí que la describa como work in progress, ya que la problemática de las desapariciones forzadas pareciera ser interminable en el contexto juarense. Acerca de la importancia de recopilar estas imágenes, Guerra anota: 


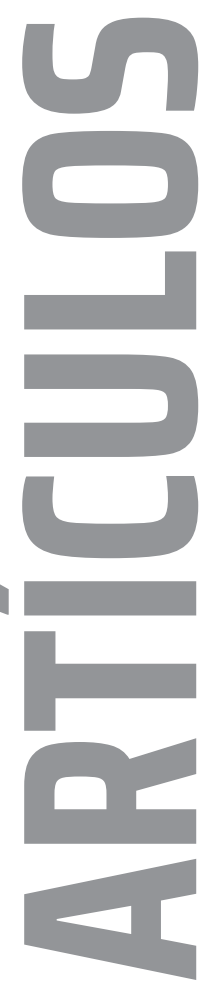

Durante el período de violencia derivada de la "guerra contra el narcotráfico» en Ciudad Juárez, las noticias que más resaltaron fueron aquellas que se les relacionaba directamente con venganzas o luchas entre carteles de la droga, extorción, secuestro, asalto, masacres, etcétera. Sin embargo, la ciudad empezó a tapizarse día a día de pesquisas que casi nadie percibía. Las estadísticas de niñas y mujeres desaparecidas incrementaron hasta duplicar el número de mujeres desaparecidas en los noventas (Guerra, comunicación personal, 23 de septiembre de 2015).
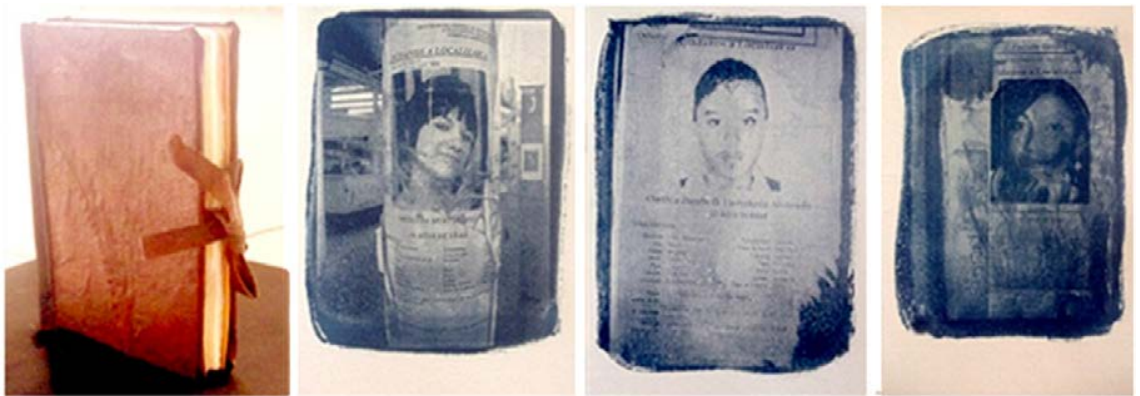

Figura 5. Sin Título (2012), de Olga Guerra. Libro de artista. Cianotipias. Dimensiones: $19 \times 13 \mathrm{~cm}$. Fotografía: Olga Guerra. Imágenes: cortesía de la autora.

\section{CONCLUSIÓN}

Artistas juarenses como Olga Guerra son quienes, más allá de hacer piezas de arte ensimismados en su propio mundo e interés personal, prefieren alejarse de esa idea clásica del artista bohemio y egocéntrico, y crear desde el prisma colaborativo; hacedores de un activismo que inmanentemente constituya la construcción de espacios que favorezcan las interrelaciones humanas para la reconstrucción del tejido social.

Este tipo de prácticas artísticas nos recuerda gratamente a aquellos planteamientos nacientes en los años noventa de la mano de Nicolas Bourriaud (2008), quien hablaba de la estética relacional, en alusión a ese tipo de movimientos artísticos en el que los artistas se involucran a tal grado en la cotidianidad contextual del espacio que anidan, que sus piezas emergen inevitablemente de las relaciones existentes entre el contexto, su persona y la sociedad: en este caso, las personas vinculadas, directa o indirectamente, con las víctimas o sobrevivientes de la violencia en Ciudad Juárez. Piezas de Guerra como Fragmentos de Oposición al Olvido (2012) buscan generar espacios de empatía y de solidaridad con los mismos familiares de las víctimas, quienes, finalmente, confiesan sentirse agradecidos por rememorar a sus seres queridos desde la cotidianidad de sus objetos y recuerdos bellos, y no a través de las frías, a veces hasta grotescas, fotografías de sus cuerpos caídos. 


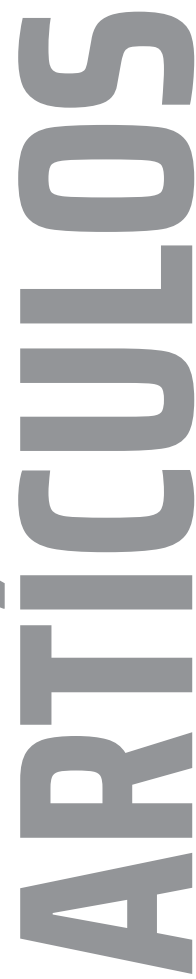

A la postre, obras como Sin Título (2012) inciden en la importancia del tema de las desapariciones forzadas. A decir de Guerra, no hay que olvidar... Mientras la ciudad bullía de temor ante los mensajes violentos de los narcotraficantes y la prensa no cesaba de publicar todo tipo de barbaries, en silencio, las paredes de las principales calles de Ciudad Juárez se iban tapizando de carteles de personas desaparecidas. Una imagen desoladora que nos hace ver cómo, a veces, el espectáculo mediático acalla la búsqueda de sus familias.

\section{REFERENCIAS}

Barrios Rodríguez, D. (2013). Las ciudades imposibles. Violencias, miedos y formas de militarización contemporánea en urbes latinoamericanas: Medellín-Ciudad Juárez (Tesis de maestría). Programa de Posgrado en Estudios Latinoamericanos de la Universidad Nacional Autónoma de México, Ciudad de México, México. Recuperado de http://132.248.9.195/ptd2013/noviembre/0706079/0706079.pdf

Bourriaud, N. (2008). Estética relacional. Ciudad Autónoma de Buenos Aires, Argentina: Adriana Hidalgo Editora.

EFE. (13 de abril de 2016). Iniciativa de desapariciones forzadas del Senado exime al Estado de responsabilidades, denuncian ONGs. El Diario sin límites.

García Pereira, R. (2010). Juárez la Fea. Ciudad Juárez, México: Universidad Autónoma de Ciudad Juárez.

Grupo de Trabajo sobre Desapariciones Forzadas o Involuntarias. (2015). Informe annual del Grupo de Trabajo sobre las desapariciones forzadas o involuntarias [Informe anual]. Recuperado de https://www.ohchr.org/SP/Issues/Disappearances/Pages/Annual.aspx

Guasch, A. M. (2005). Los lugares de la memoria: el arte de archivar y recordar. Matèria. Revista internacional d'art, 5, 157-183. Recuperado de https://revistes.ub.edu/index. $\mathrm{php} / \mathrm{materia/article/view/11382}$

Halbwachs, M. [1991] (2002). Fragmentos de la Memoria Colectiva (Trad. Aguilar, M. A.). Athenea Digital, (2), 1-11. Recuperado de https://atheneadigital.net/article/view/ n2-halbwachs/52-pdf-es

Herrera, M. C. y Olaya, V. (2011). Ciudades tatuadas: arte callejero, política y memorias visuales. Nómadas, (35), 99-116. Recuperado de http://nomadas.ucentral.edu.co/ nomadas/pdf/nomadas_35/35_6HO_Ciudadestatuadas.pdf

Martínez Toyes, W. y Arellano Quiroga, J. (2012). Movilidad poblacional: efecto de la violencia e inseguridad en Ciudad Juárez. En M. Limas (Coord.), Inseguridad y violencia en Ciudad Juárez (pp. 45-62). Ciudad Juárez, México: Universidad Autónoma de Ciudad Juárez.

Méndez Llopis, C. (2016). Disidencias artísticas en Ciudad Juárez. Prácticas colaborativas en contextos de violencia. Kultur. Revista interdisciplinària sobre la cultura de la ciutat, 3(5), 177-210. doi: 10.6035/Kult-ur.2016.3.5.8

Mínguez-García, H. (2018). Resistirse al tiempo: los libros-arte y el cultivo de la memoria. Arte, individuo y sociedad, 30(3), 519-540. doi: 10.5209/ARIS.57828

Molina, J. (26 de febrero de 2015). Las desapariciones forzosas en México: «¿Cómo confiar en un Estado criminal?». Eldiario.es. Recuperado de http://www.eldiario.es/desalambre/ desapariciones-forzosas-Mexico-confiar-criminal_0_360814819.html 


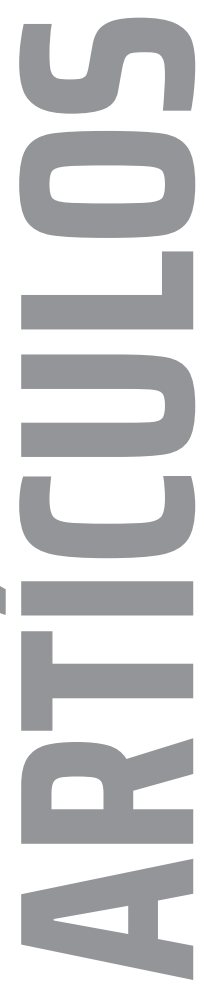

Naciones Unidas. (2009). Desapariciones forzadas o involuntarias. En Folleto informativo $N^{\circ}$ 6/Rev.3. Ginebra, Suiza: Oficina del Alto Comisionado de las Naciones Unidas para los Derechos Humanos. Recuperado de https://www.ohchr.org/Documents/Publications/ FactSheet6Rev3_sp.pdf

Sábato, E. (2006). La resistencia. Ciudad Autónoma de Buenos Aires, Argentina: Seis Barral.

Salazar, S. y Curiel, M. (2012). Ciudad abatida: antropología de la(s) fatalidad(es).ciudad Juárez, México: Universidad Autónoma de Ciudad Juárez.

Velázquez Vargas, M. S. y Martínez Canizales, G. (2012). La inseguridad en Ciudad Juárez desde la percepción de los ciudadanos. En M. Limas (Coord.), Inseguridad y violencia en Ciudad Juárez (pp. 63-82). Ciudad Juárez, México: Universidad Autónoma de Ciudad Juárez.

Villalpando, R. (28 de marzo de 2010). Falló el Operativo Conjunto Chihuahua, coinciden diversos sectores sociales. La Jornada, p. 7. Recuperado de http://www.jornada.unam. $\mathrm{mx} / 2010 / 03 / 28 /$ index.php?section=politica\&article=007n1pol 